\title{
Characterization of Newcastle Disease Virus and poultry-handling practices in live poultry markets, Ethiopia
}

\author{
Delesa Damena Mulisa ${ }^{1 *}$, Menbere Kidane W/Kiros ${ }^{1}$, Redeat Belaineh Alemu' ${ }^{1}$, Melaku Sombo Keno ${ }^{1}$, Alice Furaso ${ }^{2}$, \\ Alireza Heidari ${ }^{2}$, Tesfaye Rufael Chibsa ${ }^{1}$ and Hassen Chaka Chunde ${ }^{1}$
}

\begin{abstract}
Newcastle disease represents the most severe poultry disease responsible for marked economic losses in Ethiopia. To provide a molecular characterization of Newcastle disease viruses circulating in this country, a cross sectional survey was conducted at five selected live poultry market sites in Addis Ababa. In addition, baseline data on the live poultry market system were acquired through a detailed questionnaire submitted to poultry traders. We identified 44/146 positive samples, 29 of which were virulent strains belonging to sub-genotype VIf. The very poor biosecurity practices, which have resulted from responses of the participants, suggest that they might have had a heavy impact in the spread of the disease. This study provides important information on epidemiology and control of NDV in Ethiopia and highlights the importance of implementing surveillances and biosecurity practices in live poultry markets.
\end{abstract}

Keywords: Newcastle disease virus; Biosecurity practices; Molecular characterization; Live poultry markets; Ethiopia

\section{Introduction}

Poultry play an important economic, nutritional and sociocultural role in the livelihoods of poor rural households in developing countries, including Ethiopia. The total poultry population in Ethiopia is estimated at 43 million, 97\% of which are village chickens (Central Statistical Agency 2012). Poultry rearing is particularly important to women, who often own and manage chickens and the resulting income is often used to support education of children. Despite its role in raising incomes and reducing poverty in local communities of Ethiopia, poultry production is hampered by wide arrays of constraints among which infectious diseases, such as: Newcastle disease, Infectious Bursal Disease, Mycoplasmosis, Pasteurellosis and Salmonellosis, are the major ones (Chaka et al. 2012).

Newcastle disease(ND) is one of the major problems in village chickens in most parts of Ethiopia (Nasser 1998; Tadelle and Jobre 2004; Mazengia 2012). The disease has become endemic in poultry population and recurs every year inflicting heavy losses (Tadelle and Jobre 2004). The

\footnotetext{
* Correspondence: delesa_damenaa@yahoo.com

${ }^{1}$ National Animal Health Diagnostic and Investigation Center, Sebeta, Ethiopia

Full list of author information is available at the end of the article
}

highest rate of ND outbreaks from March to May is suggested to be associated with high rate of chicken marketing for Easter (Spradbrow 1999). The main movement of chicken marketing is from periphery to the center (rural to towns) which favors the spread of diseases all over the country (Dessei and Ogle 2001). However, there is acute lack of information on bio-security situation and roles of poultry marketing practices in diseases dissemination in the country (Shewantasew et al. 2012).

ND is caused by virulent strains of Newcastle diseases virus (NDV) or avian paramyxovirus type 1 (APMV-1) that belongs to the genus Avula and family Paramyxoviridae (Mayo 2002). NDV has an enveloped, single-stranded negative sense RNA genome of approximately $15 \mathrm{~kb}$ that contains six genes encoding major structural proteins such as: nucleocapsid protein (NP), phosphoprotein $(\mathrm{P})$, matrix protein $(\mathrm{M})$, fusion protein $(\mathrm{F})$, hemagglutinin-neuraminidase $(\mathrm{HN})$, and the RNA- dependent RNA polymerase $(\mathrm{L})$ (Kattenbelt et al. 2006) as well as two additional proteins, V and W from the P gene by a mechanism called RNA editing (Steward et al. 1993).

The key contributors to NDV pathogenicity are the formation of an active fusion protein upon cleavage of the $\mathrm{F}$ protein precursor $(\mathrm{F} 0)$ as well as the presence of a 
number of basic residues in the fusion protein cleavage site (Toyoda et al. 1987; Glickman et al. 1988).

NDV that are virulent for chickens have a multibasic amino acid sequence ${ }^{112} \mathrm{R} / \mathrm{K}-\mathrm{R}-\mathrm{Q}-\mathrm{K} / \mathrm{R}-\mathrm{R}^{116}$ at the Cterminus of the $\mathrm{F} 2$ protein and $\mathrm{F}$ (phenylalanine) at residue 117 , which is the $\mathrm{N}$-terminus of the F1 protein, whereas the viruses of low virulence have a monobasic amino acid sequences in the same region of ${ }^{112} \mathrm{G} / \mathrm{E}-\mathrm{K} / \mathrm{R}-\mathrm{Q}-\mathrm{G} / \mathrm{E}-\mathrm{R}^{116}$ and L (leucine) at residue 117 (Kim et al. 2008; Office of International Epizootes 2012).

Although ND represents the most severe poultry disease responsible for marked economic losses in Ethiopia, virological and epidemiological information concerning the virus strains circulating in the country especially in village chickens are extremely scarce. The aim of this study was therefore, to detect NDV and to perform a molecular characterization of the virulent strains currently circulating at five live poultry market sites in Addis Ababa. In addition, we investigated the biosecurity practices implemented at the market sites to identify the factors that can contribute to the spread of the virus.

\section{Materials and methods}

\section{Sample origin}

The study was conducted in December 2012 in five live poultry market sites in Addis Ababa namely: Kotebe, Merkato, Shola, Saris and Semen (Adisu gebeya) (Figure 1). These are among the biggest poultry market sites in Addis Ababa that host chickens originating from most parts of the country, mainly from places located within $300 \mathrm{kms}$ radius such as: Sodo, Hosaina, Dessie, Shashemane, Jimma, and Ambo. All the markets are outdoor markets where chickens are kept in wire mesh cages, each housing up to 40 birds during the day and night.

\section{Sampling, data collection and virus isolation}

A total of 365 chickens were sampled: From each market, 70 birds were sampled except Merkato from where 85 birds were sampled by considering its larger size compared to the others. Thus, 73 tracheal swabs (pool of five) and 73 cloacal (pool of five) were collected. In separate cryovial containing $2 \mathrm{ml}$ of freshly prepared viral transport media (VTM).

The swabs were collected in pairs (Tracheal swab pools and Cloacal swab pools were always collected from the same chickens). After sampling, the specimens were transported to the National Animal Health Diagnostic and Investigation Center (NAHDIC) laboratory and stored at $-80^{\circ} \mathrm{C}$ until processing. Besides, a standardized questionnaire was administered to the poultry traders in each market sites. A total of 100 volunteer traders were interviewed to assess the bio-security practices in live poultry markets. The questionnaire included questions about the source of the birds, means of transportation, the number of birds in each market site, cleaning practices at the market sites including the cages, health status of the birds and disposal of manures and dead chickens.

Viruses were isolated from the swab samples by standard virus isolation methods in embryonated chicken eggs. Three embryonated chicken eggs of 9 to 11-day-old per sample were used for inoculation (Alexander and Senne 2008). The inoculated eggs were candled every 24 hours to check embryo vitality. Eggs containing dead embryo on each day and those remained at the end of

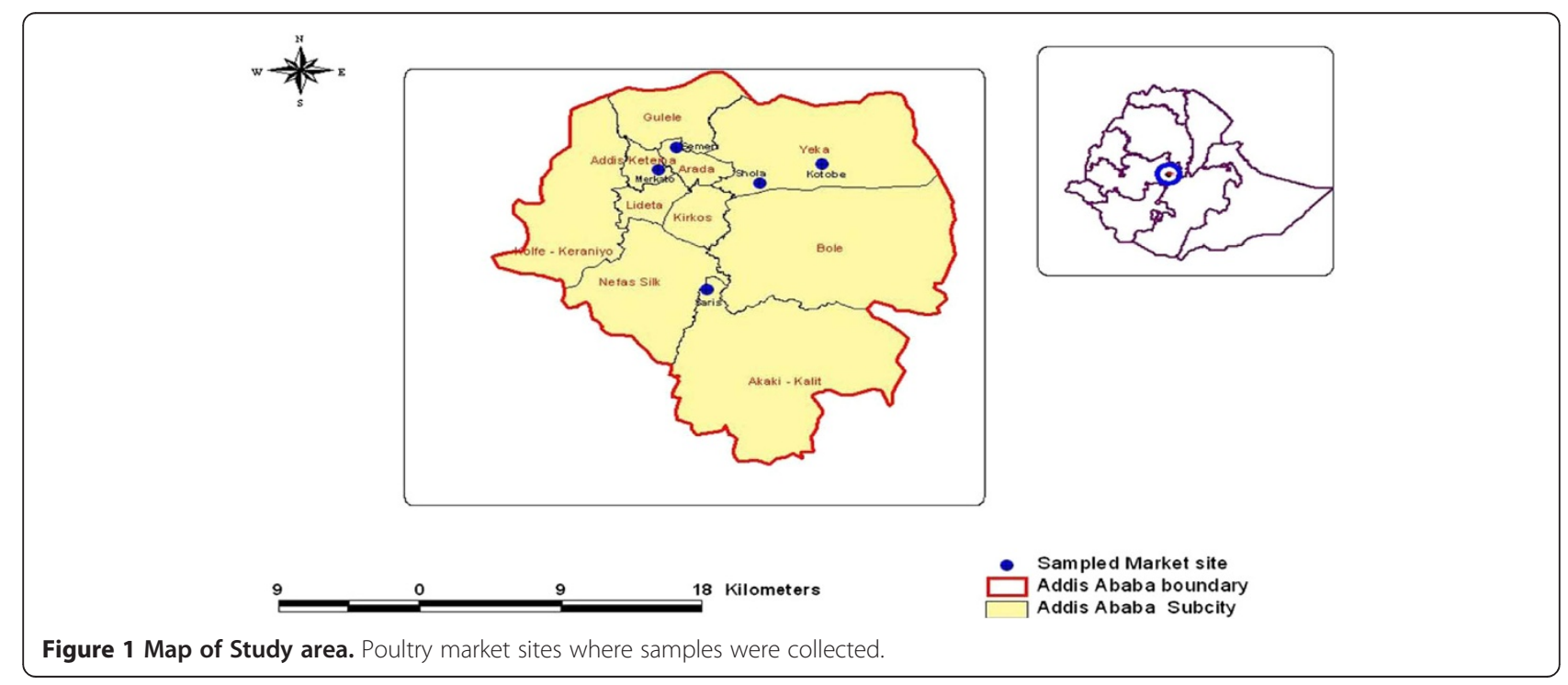


incubation period, were removed from incubator and chilled at $+4^{\circ} \mathrm{C}$ overnight. Allantoic fluids were harvested and tested by Haemagglutination (HA) test for its ability to haemagglutinate chicken RBCs.

\section{Haemagglutination and Haemagglutination Inhibition tests}

The HA assay was carried out in microtitre plate as outlined by the World Organization for Animal Health (Office of International Epizootes 2012). HA positive samples were tested by Heamaglutination Inhibition (HI) reaction to specifically determine the haemagglutinating agents. Inactivated antigen for HA test and positive and negative sera for HI controls were obtained from Istituto Zooprofilattico Spermentale delle Venezie (OIE/FAO Reference Laboratory for AI and ND), Padua, Italy.

\section{Polymerase Chain Reaction tests}

Forty four HA and HI positive allantoic fluids were analyzed by real- time reverse transcription (RT-PCR) tests. Viral RNA extraction from $\mathrm{HI}$ positive allantoic fluid was conducted using Qiagen ${ }^{\circledR}$ RNeasy Mini kit according to manufacturer's instruction. Real-time RT-PCR reactions were performed at National Animal Health Diagnostic Center, Sebeta using an Applied Biosystems 7500 Fast Real-Time PCR thermo cycler. A primer probe combination from conserved region of $M$ gene APMV-1 F M + 4100 5'-AGT GAT GTG CTC GGA CCT TC-3', APMV-1 R M-4220 5'-CCT GAG GAG AGG CAT TTG CTA-3' and Probe APMV-1 Probe $M+4169$ 5'- FAMTTC TCT AGC AGT GGG ACA GCC TGC BHQ-3' (Wise et al. 2004) was used to amplify and detect all NDV isolates. The M-gene positive samples were re-run by a second primer-probe set targeting the $\mathrm{F}$ gene Forward F + 4829 5'-GGT GAG TCT ATC CGG ARG ATA CAA G-3', Reverse Primer F- 4939 5'-AGC TGT TGC AAC CCC AAG-3' and Probe F+4894 5'-FAM-AAG CGT TTC TGT CTC CTT CCT CCA-BHQ-3' (Wise et al. 2004) to specifically amplify and detect only pathogenic strains of NDV. Twenty nine F gene Positive allantoic fluids were submitted to Instito Zooprofilattico Sperimentale delle Venezie (OIE/FAO Reference Laboratory for AI and ND), Padua,Italy for further analyses.

\section{Nucleotide Sequencing and phylogenetic analysis}

Total RNA was extracted from infective allantoic fluids using Qiagen ${ }^{\odot}$ RNeasy Mini kit according to manufacturer's instruction. Amplification was performed with primers NOH-For (5'-TAC ACC TCA TCC CAG ACA GG-3') and NOH- Rev (5'-AGT CGG AGG ATG TGT TGG CAG C-3') which encompass 260 bp region of the fusion (F) gene. Amplicons were then purified with ExoSAP-IT (USB Corporation, Cleveland, OH). Sequencing was carried out by using Big Dye Terminator v 3.1 cycle sequencing kit (Applied Biosystems, Foster City, CA, USA) in a 16-cappilary ABI PRISM 3131x Genetic Analyzer (Applied Biosystems, Forster City, CA,USA).

For complete sequencing of $\mathrm{F}$ gene, RNA was reverse transcribed with the Superscript III Reverse Transcriptase kit (Invitrogen, Carsbad, CA, USA) and amplified using primer pairs described in Table 1. Sequence data were assembled and edited with Seq Scape software v2.5 (Applied Biosystems). To determine the phylogenetic relationships, the sequences of the F gene were compared to the corresponding region of representative viruses of class II available in GenBank. Alignment and comparison of the nucleotide and amino acid sequences were performed using Clustal W in MEGA 5.0. Maximum likelihood (ML) trees were estimated using best-fit general time-reversible (GTR) model of nucleotide substitution with gammadistributed rate variation among sites, and a heuristic SPR branch-swapping search available in PhyML version 3.0 (Guindon and Gascuel 2003). A bootstrap resampling process (100 replications) was employed to assess the robustness of individual nodes of phylogeny.

\section{Results}

\section{Marketing practices}

Chickens present at each market were estimated to be $300-500$ on the days of visit. They are originated from different districts across the country, most of which were collected by traders from big towns such as: Sodo, Dessie, Shashemane, Jimma, Ambo, Hosaina and transported on public transport (bus) to Addis Ababa. The majority (99\%) of traders mentioned that there is no habit of cleaning buses before loading and after unloading chickens owing to the fact that no vehicles is designed for poultry transportation alone. After arrival at the market sites, chickens are sold to wholesalers in the biggest live bird market site

Table 1 Primers set for amplification of complete F-gene

\begin{tabular}{ll}
\hline Primers & Sequence $\mathbf{5}^{\prime}$ to $\mathbf{3}^{\prime}$ \\
\hline MF3710-F & TGA AAA CGA CGG CCA GTC AAA GCT GTA DGG TTG TG \\
MF4650-R & CAG GAA ACA GTA TGA CCA AGA GGC CTG CCR TCA A \\
F5100-F & TGA AAA CGA CGG CCA GTA TGC AGC ART TTG TYA AT \\
HF011-R & CAG GAA ACA GTA TGA CCT ARG TAA TRA GAG CRG ATG \\
HF005-F & TGA AAA CGA CGG CCA GTA GAC YGA AGG CGC ACT YAC \\
HH008-R & CAG GAA ACA GTA TGA CCA GRG CCA CYT GCT TRT ATA \\
F-4514-F & TGA AAA CGA CGG CCA GTG TAG AAG ADT YTG GAT CC \\
F-5218-R & CAG GAA ACA GTA TGA CCG AAT ACY GTA GTC AAY TCR G \\
HF009-R & CAG GAA ACA GTA TGA CCA GGT GGC ACG CAT ATT ATT \\
F-5757-F & TGA AAA CGA CGG CCA GTA GAT RAC AAC ATG TAG RTG \\
F-6449-R & CAG GAA ACA GTA TGA CCG GCT AAC YGC RCG GTC CAT \\
\hline
\end{tabular}


(Merkato) where birds from different origins are placed in the same cages (mixed) and sold either to traders in other live poultry markets in the city or to the consumers on spot. Ninety nine percent of the traders clean the holding cages once a week with clean water and the remaining $1 \%$ clean every day. All the traders responded that they dispose manure and dead birds either within the markets or on roadside. None of them seek for veterinary services when chickens are sick.

\section{Laboratory results}

Out of the 146 pooled samples tested, 44 were positive for NDV by both HA/HI and M gene real-time RT-PCR tests. Out of these, 29 isolates were identified as virulent based on the real-time RT-PCR of F gene. Among these, 14. Tracheal swab pools (TS) were positive though the corresponding Cloacal swab pools (CS) were negative. Similarly, 3 CS were positive though the corresponding TS were negative. However, the remaining 12 swab pools have shown direct correlation (12 TS and the corresponding 12 CS were positive) and were not considered as separate entity to avoid double counting of the samples (Table 2). The identification, pathotyping and genotyping of the 29 isolates were confirmed by genetic sequencing of the $260 \mathrm{bp}$ region of fusion $(\mathrm{F})$ gene and the complete $\mathrm{F}$ gene sequence of two isolates (KJ958913_13VIR3936-1 and KJ958914_13VIR3936-27) collected from the market sites Saris and Kotebe. Since all the viruses showed a high similarity at the $260 \mathrm{bp}$ region of the F gene (Table 2), the selection was based on the sequencing quality (i.e. absence of degenerate bases).The isolates were identified as virulent as deduced amino acid sequence of the fusion protein cleavage site indicated the presence of motif ${ }^{112}$ RRQKR ${ }^{116 *} \mathrm{~F}^{117}$ typical of NDV virulent strains. Phylogenetic analysis of the 260 fragment of the $F$ gene of all the 29 sequenced isolates (Additional file 1: Figure S1) and complete coding region of the $\mathrm{F}$ gene of two representative viruses (Figure 2) indicated that the viruses are clustered together (similarity ranged from 98\% to $100 \%$ ) within the new sub-genotype VIf.

\section{Discussion}

In this study, we assessed biosecurity practices in market sites in Addis Ababa that contribute to the spread of the diseases along market chain. We observed several practices that could promote Newcastle disease and other infectious diseases transmission among birds. These included limited cleaning and disinfection of the market places, holding cages, mixing of birds from different origins, inappropriate disposal of sick and dead birds and poor waste disposal mechanisms. Earlier reports indicated that marketing systems play a considerable role in the dissemination of diseases over wide geographical areas in a relatively short period of time in Ethiopia (Gebreab 1995). Similar observation was reported from Addis Ababa live poultry market sites (Shewantasew et al. 2012). The current finding is also in agreement with a report from Nairobi live bird markets where poor biosecurity practices were suggested to play major roles for transmission of avian influenza viruses (Munyua et al. 2012). These factors were found to be associated with transmission of low pathogenic avain influenza viruses in markets in North America (Garber et al. 2007).

The current study showed that, virulent viruses with multiple basic amino acids at cleavage site of $\mathrm{F}$ protein ${ }^{112} \mathrm{RRQKR} \mathrm{R}^{116 *} \mathrm{~F}^{117}$ are circulating in village chickens. The finding is in agreement with earlier studies which revealed that, the majority of the virus strains circulating in the village chickens in Ethiopia are virulent strains (Chaka et al. 2012). Virulent Newcastle disease virus (vNDV) is endemic in many countries of Africa, North, Central, and South America, and outbreaks of ND are frequently reported to the World Organization of Animal health (Office of International Epizootes 2011).

According to Diel et al. (2012) classification, our phylogenetic analysis of the 260 fragment of the fusion gene of all the 29 sequenced isolates (Additional file 1: Figure S1) indicated that the viruses are grouped in the new subgenotype VIf class II viruses, and grouped with NDV identified in Ethiopia (de Almeida et al. 2013; Chaka et al. 2013). The genotype was confirmed by analysis of complete coding region of the $\mathrm{F}$ gene of two representative viruses (Figure 2), which showed $95 \%$ to $99.3 \%$ similarity

Table 2 Origin of positive swab pools and their genetic identity with reference sequence

\begin{tabular}{|c|c|c|c|c|c|c|}
\hline \multirow{2}{*}{$\begin{array}{l}\text { Market sites from } \\
\text { where the samples } \\
\text { were collected }\end{array}$} & \multirow{2}{*}{$\begin{array}{l}\text { Number of } \\
\text { M-gene real time } \\
\text { RT PCR positive } \\
\text { swab pools }\end{array}$} & \multicolumn{4}{|c|}{ Number of F-gene(virulent) real time RT PCR positive swab pools } & \multirow{2}{*}{$\begin{array}{l}\text { Genetic identity } \\
\text { with the reference } \\
\text { sequence at the } \\
260 \text { bp region } \\
\text { of the F gene }\end{array}$} \\
\hline & & Total & Both TS \&CS & Only TS & Only CS & \\
\hline Shola & 12 & 8 & 4 & 4 & 0 & 98 to $100 \%$ \\
\hline Meri & 9 & 5 & 4 & 1 & 0 & 98.7 to $100 \%$ \\
\hline Saris & 7 & 3 & 2 & 0 & 1 & 99.3 to $100 \%$ \\
\hline Merkato & 10 & 9 & 2 & 5 & 2 & $100 \%$ \\
\hline Kotebe & 6 & 4 & 0 & 4 & 0 & $100 \%$ \\
\hline
\end{tabular}




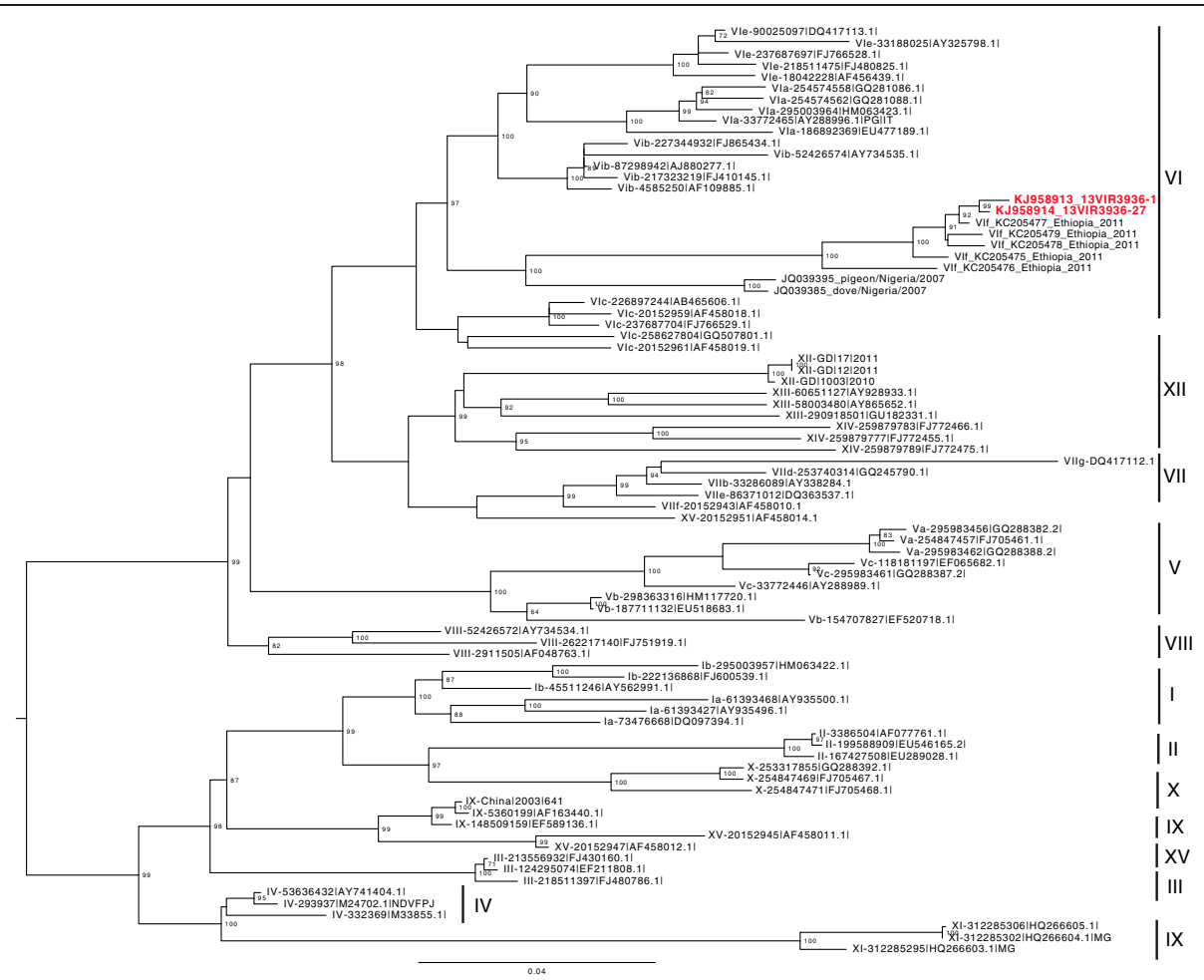

Figure 2 Phylogenetic tree of the complete nucleotide sequence of the $\mathrm{F}$ gene for two representative isolates. ML Phylogenetic tree of complete nucleotide sequence of Class II Newcastle diseases viruses. Ethiopian isolates included in this analysis (KJ958913_13VIR3936-1 and KJ958914_13VIR3936-27) are labeled in red. The Nomenclature system used in the phylogenetic tree is based on (Diel et al.2012). The numbers at branch points represent bootstrap values.

with the NDV isolated in 2011 suggesting the persistence of this sub-genotype in poultry in the country. While the 260 nucleotide sequences of samples collected from the market sites of Merkato and Kotebe were all identical, sequences of viruses from Saris, Shola and Meri showed a nucleotide identity ranging from $99.3 \%$ to $100 \%$, from $98 \%$ to $100 \%$ and from $98.7 \%$ to $100 \%$, respectively). Which revealed that, identical isolates are circulating in livebird markets in Addis Ababa. This could be associated with the poor biosecurity practices and the use of similar marketing channel in these market sites. However, Fentie et al. (2013) identified genotype VII viruses in the North western Ethiopia, indicating the co-circulation of different genotypes in Ethiopia. Genotype VI, include viruses that have been isolated from multiple avian species (Alexander 2011; Czeglédi et al. 2006; Kim et al. 2008). Viruses of this group are important because of their frequent association with doves and pigeons and consequent risk for introduction in to poultry flocks (Alexander 2011; Kim et al. 2008). It is interesting to note that Ethiopian viruses analyzed here grouped with viruses collected in Nigeria from pigeon and doves (identity of about $90 \%$ ), suggesting that this genotype may have emerged in Africa as a result of transmission from pigeon to poultry.
In conclusion, the current study revealed that village chicken flocks are endemically infected with virulent Newcastle disease virus, which could pose a threat to commercial poultry farms. This study highlights the importance of implementing surveillance and molecular investigations of Newcastle disease, in village chickens and wild birds, along with improved biosecurity measures in the live poultry markets in Ethiopia.

\section{Additional file}

Additional file 1: Phylogenetic tree of the 260 fragment of the $F$ gene of all the 29 sequenced isolates.

\section{Competing interests}

The authors have declared that no competing interests exist.

\section{Authors' contributions}

DD conceived and designed the study, participated in data collection, laboratory analysis and drafted the manuscript, MK participated in data collection, laboratory analysis and helped in drafting of the manuscript, RB and MS participated in data collection and laboratory analysis, AF carried out the sequencing, sequence alignment and phylogenetic reconstruction and revised the manuscript, $\mathrm{AH}$ participated in sequence alignment and phylogenetic reconstruction, TR participated in design and coordination of the work. HC participated in drafting and edition of the manuscript. All authors read and approved the final manuscript. 


\section{Acknowledgements}

This study was supported by National Animal Health Diagnostic center, Ethiopia. The authors would like to thank the molecular Biology Laboratory staff of NAHDIC, Ethiopia, and Istituto Zooprofilattico Sperimentale delle Venezie,Italy for their technical assistance and support in processing of the samples and genetic analysis of the isolates.

\section{Author details}

${ }^{1}$ National Animal Health Diagnostic and Investigation Center, Sebeta, Ethiopia. ${ }^{2}$ Research and Innovation Department, Istituto Zooprofilattico Sperimentale delle Venezie, OIE/FAO and National Reference Laboratory for Newcastle Disease and Avian Influenza,OIE collaborating Center for Diseases at the Human-Animal Interface, Legnaro, Padova, Italy.

Received: 1 April 2014 Accepted: 18 August 2014 Published: 23 August 2014

\section{References}

Alexander DJ (2011) Newcastle disease in the European Union 2000 to 2009. Avian Pathol 40(6):547-558

Alexander DJ, Senne DA (2008) Newcastle disease, other avian paramyxoviruses, and pneumovirus infections. In: Saif YM, Fadly A, Glisson JR, Mc D, Larry R, Nolan LK, Swayne D (eds) Diseases of Poultry, 12th edn. Blackwell Publishing, Ames, IA, pp 750-798

Central Statistical Agency (2012) Agricultural Sample Survey (2011/12) Volume II, Report on Livestock and Livestock characteristics, Statistical Bulletin, 505. Addis Ababa, Ethiopia

Chaka H, Goutard F, Bisschop SPR, Thompson PN (2012) Seroprevalence of Newcastle disease and other infectious diseases in backyard chickens at markets in Eastern Shewa zone, Ethiopia. Poult Sci 91:862-869

Chaka H, Goutard F, Gil P, Abolnik C, Servan De Almeida R, Bisschop S, Thompson PN (2013) Serological and molecular investigation of Newcastle disease in household chicken flocks and associated markets in Eastern Shewa zone, Ethiopia. Tropl Anim Health Prod 45(3):705-714

Czeglédi A, Ujvári D, Somogyi E, Wehmann E, Werner O, Lomniczi B (2006) Third genome size category of avian paramyxovirus serotype 1 (Newcastle disease virus) and evolutionary implications. Virus Res 120(1-2):36-48

De Almeida RS, Hammoumi S, Gil P, Briand FX, Molia S, Gaidet N, Cappelle J, Chevalier V, Balanc G, Traore A, Grillet C, Maminiaina OF, Guendouz S, Dakouo M, Samake K, Bezeid OEM, Diarra A, Chaka H, Goutard F, Thompson P, Martinez D, Jestin V, Albina E (2013) New avian paramyxoviruses type I strains identified in Africa provide new outcomes for phylogeny reconstruction and genotype classification. PLoS One 8(10):76413

Dessei T, Ogle B (2001) Village poultry production system in the central highlands of Ethiopia. Tropl Anim Health Prod 33:521-537

Diel DG, Da SLHA, LiuH WZ, Miller PJ, Afonso CL (2012) Genetic diversity of avian paramyxovirus type 1: Proposal for a unified nomenclature and classification system of Newcastle disease virus genotypes Infection. Genet Evol 12:1770-1779

Fentie T, HeidariA AR, Kassa T, Capua I, Cattoli G, Sahle M (2013) Molecular characterization of Newcastle disease viruses isolated from rural chicken in northwest Ethiopia reveals the circulation of three distinct genotypes in the country. Tropl Anim Health Prod 10:11250-11263

Garber L, Voelker L, Hill G (2007) Description of live poultry markets in the United States and factors associated with repeated presence of $\mathrm{H} 5 / \mathrm{H} 7$ lowpathogenicity avian influenza virus. Avian Dis 51:417-420

Gebreab F (1995) Zoonotic diseases in Ethiopia. Ethiopian Society of Animal Production. Addis Ababa, Ethiopia

Glickman RL, Syddall RJ, lorio RM, Sheehan JP, Bratt MA (1988) Quantitative basic residue requirements in the cleavage-activation site of the fusion glycoprotein as a determinant of virulence for Newcastle disease virus. J Virol 62:354-356

Guindon S, Gascuel O (2003) A simple, fast, and accurate algorithm to estimate large phylogenies by maximum likelihood. Syst Biol 52:696-704

Kattenbelt JA, Stevens MP, Gould AR (2006) Sequence variation in the Newcastle disease virus genome. Virus Res 116(1-2):168-184

Kim LM, King DJ, Guzman H, Tesh RB, Travassos DA, Rossa APA, Bueno R, Dennet JA, Afonso CL (2008) Biological and phylogenetic characterization of pigeon paramyxovirus serotype 1 circulating in wild North American pigeons and doves. J Clin Microbiol 46(10):3303-3310

Mayo (2002) A summary of taxonomic changes recently approved by ICTV. Arch Virol 147:1655-1656
Mazengia H (2012) Review on major viral diseases of chickens reported in Ethiopia. J Infect Dis Immun 4(1):1-9

Munyua MP, Githinji WJ, Waiboci WL, Njagi ML, Arunga G, Mwasi L, Mbabu MR, Macharia MJ, Breiman FR, Njenga KM, Katz AM (2012) Detection of influenza A virus in live bird markets in Kenya, 2009-2011. Influenza Other Respi Viruses 10:1750-2659

Nasser M (1998) Oral Newcastle disease vaccination trial and studies of Newcastle disease in Ethiopia. (M.Sc. Thesis). AddisAbaba University and Freie Universitat, Addis Ababa, Ethiopia and Berlin, Germany

Office of International Epizootes (2011) World Animal Health Information Database (WAHID) Interface. http://web.oie.int/wahis/public.php? page_home\&WAHIDPHPSESSID4d95e8777ff8b8a615b31617ac4c7835

Office of International Epizootes (2012) Newcastle Disease. Manual of Diagnostic Tests and Vaccines for Terrestrial Animals, Paris, France, chapter 2.3.14

Shewantasew M, Melesse B, MesfinS MB (2012) Assessment of Bio-security situation and practices in live poultry Markets of Addis Ababa, Ethiopia. Asian J Anim Vet Adv 7(5):421-433

Spradbrow PB (1999) Epidemiology of Newcastle Disease and the Economic of its control. In: Proceedings of international workshop on Poverty eradication and promotion of gender equality, held at Livestock Research Institute 26-26 March 1999. Tune landboskole, Denmark, pp 165-173

Steward M, Vipond IB, Millar NS, Emmersion PT (1993) RNA editing in Newcastle disease virus. Journal of General Virology 74:2539-2547

Tadelle, Jobre $Y$ (2004) A review of the importance and control of Newcastle disease in Ethiopia. Ethiop Vet $J$ 1:71-81

Toyoda T, Sakaguchi T, Imai K, Inocencio NM, Gotoh B, Hamaguchi, Nagai Y (1987) Structural comparison of the cleavage-activation site of the fusion glycoprotein between virulent and avirulent strains of Newcastle disease virus. Virology 158:242-247

Wise MG, Suarez DL, Seal BS, Pedersen JC, Senne DA, King DJ, Kapczynski DR, Spackman E (2004) Development of a real-time reverse-transcription PCR for detection of Newcastle disease virus RNA in clinical samples. J Clin Microbiol 42(1):329-338

doi:10.1186/2193-1801-3-459

Cite this article as: Delesa et al:: Characterization of Newcastle Disease Virus and poultry-handling practices in live poultry markets, Ethiopia. SpringerPlus 2014 3:459.

\section{Submit your manuscript to a SpringerOpen ${ }^{\circ}$ journal and benefit from:}

- Convenient online submission

- Rigorous peer review

- Immediate publication on acceptance

- Open access: articles freely available online

- High visibility within the field

- Retaining the copyright to your article

Submit your next manuscript at springeropen.com 